\title{
Shortening tool setting time for transfer presses
}

B-A Behrens, E Doege ${ }^{\dagger}$, and R Krimm*

Institute for Metal Forming and Metal Forming Machine Tools (IFUM), University of Hanover, Germany

The manuscript was received on 23 August 2004 and was accepted after revision for publication on 26 September 2005.

DOI: $10.1243 / 095440505 X 32940$

\begin{abstract}
The production processes of sheet metal products with complex geometries often use transfer presses to obtain fully formed workpieces from a single machine. The job of adjusting a new multistage tool set increases with the number of stages because the deformations of the frame, the bottom platen, and the ram vary with the different applied loads. Each of the forces applied by the stages causes a specific deformation of the machine, while each stage is also influenced by all other stages. The Institute for Metal Forming and Metal Forming Machine Tools (University of Hanover, Germany) has developed a new computer-based setup system for multistage tools. Once the machine properties have been measured, the system calculates the deformation of the machine on the basis of the forming forces measured during the tool setting process. The use of the developed system will help to shorten the first set-up of new tool sets. Manufacturers of sheet metal products are expecting significant time savings.
\end{abstract}

Keywords: tool setting, transfer presses, set-up time

\section{INTRODUCTION}

Multifunctional sheet metal parts are vital today. The production process of sheet metal parts involves several forming operations with high precision requirements, e.g. in the automobile supply industry, often using transfer presses.

Figure 1 shows a spectrum of common precision parts manufactured on transfer presses. This type of press allows different forming operations to be carried out during a single ram stroke by means of a multistage tool set. A transfer device transports the workpieces from one stage to the next. Productivity is considerably higher by comparison with singlestage tools. Nevertheless, production on multistage tool sets is often in competition with production on progressive dies. In progressive dies the stages are assembled in a body on a base plate. The transport between the stages is realized by sheet metal strips remaining connected to the workpieces until they reach the last stage. The productivity of progressive dies is higher than the productivity of multistage

\footnotetext{
${ }^{\dagger}$ Deceased

*Corresponding author: Universität Hannover, Produktionstechnisches Zentrum, IFUM, Schönebecker Allee 2, D-30823, Germany.email: krimm@ifum.uni-hannover.de
}

tool sets. On the other hand, multistage tool sets allow higher degrees of deformation and less material is consumed. Multistage tool sets are substantially easier to adapt to subsequent changes if these should become necessary $[\mathbf{1}]$. However, the initial adjustment process of such tools is very complex.

\section{INITIAL SITUATION}

During the initial installation of a new tool set, the individual stages are installed in the press and tested one by one. Any necessary metal finishing [2] and the adjustment of the horizontal position of the tool parts is carried out during this stage. In particular, the daylight for each stage is adjusted. The adjustment involves ensuring that production samples pressed in each individual stage have the desired intermediate geometry between the stages (Fig. 2, left).

After testing of the last stage, this 'step-by-step' method allows the production of precision components. The workpieces are transported hand-operated transfers from one stage to the next. The press is loaded one stage at any time only. This situation changes after testing and adjustment of the stages. At this time the transfer device is installed (Fig. 2, right) and the press is loaded by all forming stages 
at the same time. The deformation of the press will be different under the new conditions. The daylights of the stages will no longer be suitable for the production of quality components. Basically, the daylight of each and every stage has to be varied experimentally in a time-consuming and iterative procedure until the desired intermediate geometry is achieved again. The result of this procedure depends on both the experience of the operator and the machine. This long-winded process to determine the daylights of the forming stages for multistage tools can take up to 20 working days.

\section{PURPOSE}

One of the research projects at the IFUM sought to develop a new model for transfer presses in order to enhance the economic potential of these machines. Software can compute the necessary daylight adjustments between the machine loaded by one stage (Fig. 2, left) on the one hand and the fully set-up press (Fig. 2, right) on the other. The modus operandi upon which the software is based is shown in Fig. 3.

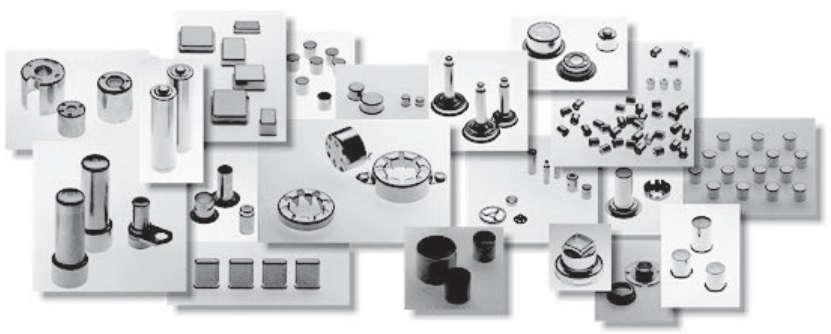

Fig. 1 Spectrum of small articles manufactured on transfer presses
The properties of the tool set and the transfer press are needed as input. Tool set properties comprise the force-path dependencies of all stages producing good-quality components. They are measured after the initial adjustment of the individual stages. This must also be done during each initial adjustment of a new tool set. The machine properties have to be determined at one time for each press in an adapted measurement procedure. Using these data, the model is able to compute the frame spring as well as the deformation of the bottom platen and the ram under different load conditions. Calculating the daylight differences between different set-up states can substantially decrease overall set-up time.

\section{BASIC APPROACH}

\subsection{Deformation of the bottom platen and ram}

To calculate the deformation of the bottom platen and ram, a basic approach was adopted after the superimposition principle. This assumes that superimposed forces in a constructional element cause superimposed deformations of that element. This principle is valid only for linear dependencies between forces and related deformations [3]. The bottom platen and the ram meet this precondition because, in this investigation, the respective deformations are considered as small [4]. To calculate the total dislocation between ram and bottom platen, non-linear effects have to be considered, as described in section 4.2. The load applied on an individual tool stage causes a dislocation on the loaded stage as well as all other stages. In the notation $\Delta z_{i j}$, $i$ indicates the stage for which the dislocation should be determined by means of equation (1), and $j$

\section{2. installation of transfer device}

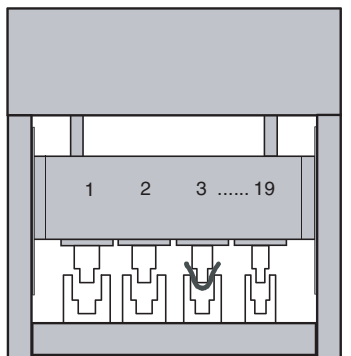

loaded by only one forming stage

hand-operated part transfer

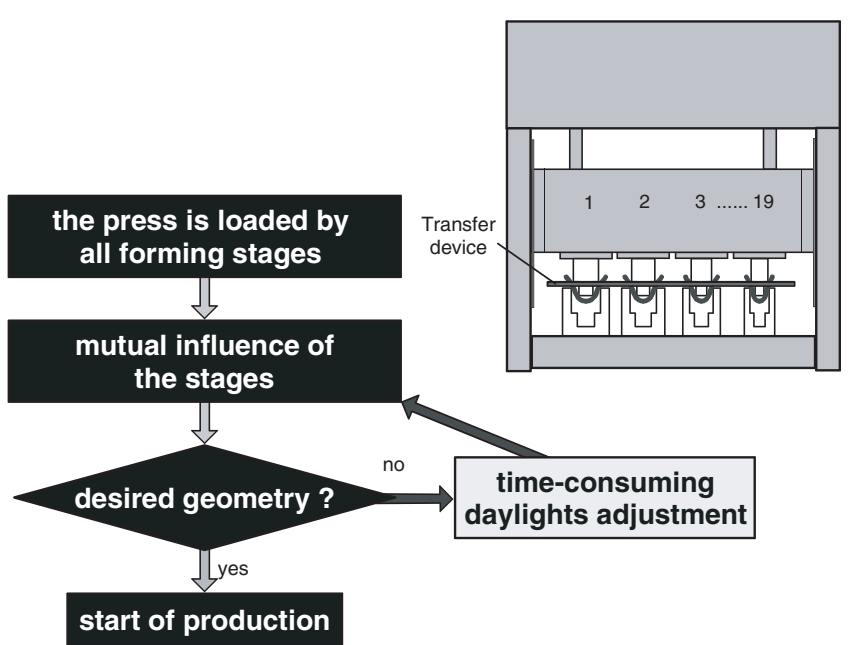

start of production

Fig. 2 Initial adjustment of transfer tool set 


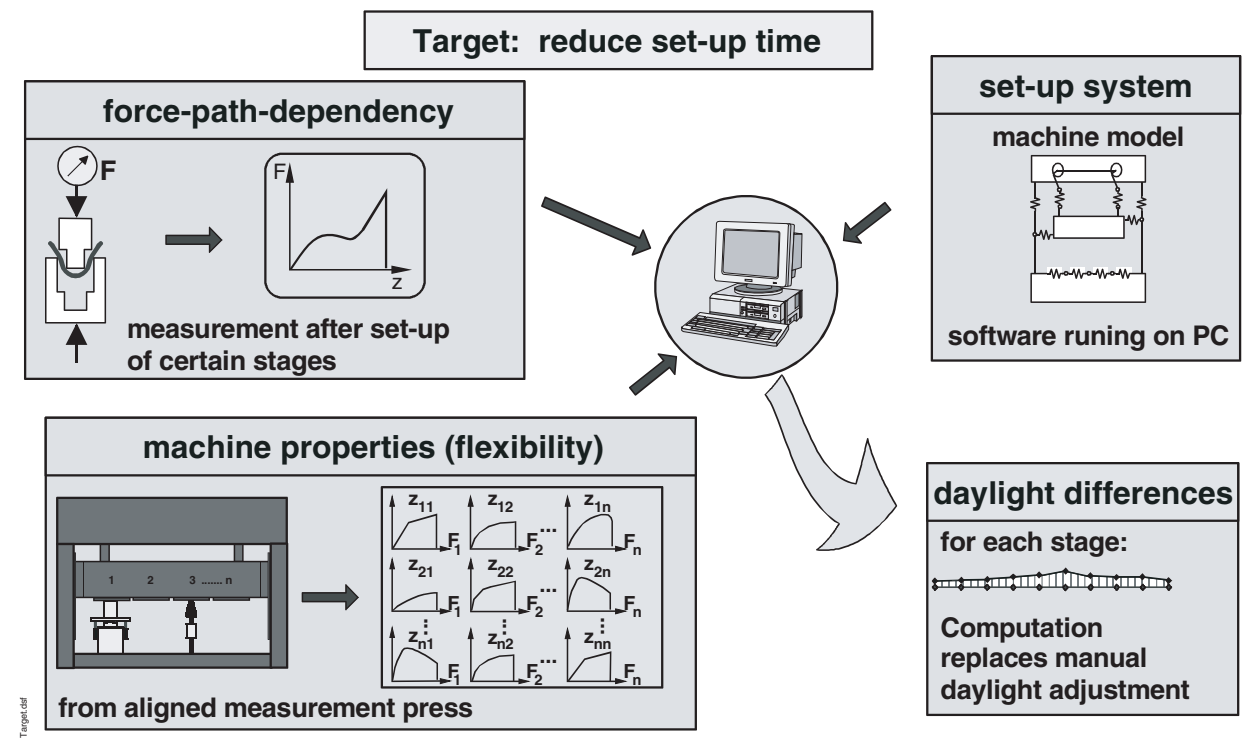

Fig. 3 Decrease in adjusting time with new set-up system

indicates the stage whose load causes a dislocation on stage $i$. As shown in Fig. 4, for example, the load on stage 1 causes a dislocation on stage $1\left(\Delta z_{11}\right)$, and also on the other stages $\left(\Delta z_{11}, \Delta z_{21}, \ldots, \Delta z_{\mathrm{n} 1}\right)$. The same applies to all other stages.

The effect of the dislocation, which is caused by a defined load in one stage on all the other stages, is determined using the press measurement results. When calculating the dislocation of a certain stage $i$ under the load of all stages, all dislocations are added as caused on stage $i$ by the loaded stages

$$
\Delta z_{i}=\Delta z_{i 1}+\Delta z_{i 2}+\Delta z_{i 3}+\cdots+\Delta z_{i n}
$$

The stiffness $c_{i j}$ can be defined by dividing the applied force on stage $j$ by the relevant dislocation on stage $i$

$$
c_{i j}=\frac{F_{j}}{\Delta z_{i j}}
$$

Substitution of $\Delta z$ in equation (1) leads to

$$
\Delta z_{i}=\frac{F_{i 1}}{c_{i 1}}+\frac{F_{i 2}}{c_{i 2}}+\frac{F_{i 3}}{c_{i 3}}+\cdots+\frac{F_{i n}}{c_{i n}}
$$

Equation (3) can be established for all stages. These equations for all stages can be summarized in matrix form.

$$
\Delta \boldsymbol{z}=\boldsymbol{N} \cdot \boldsymbol{F}=\left[\begin{array}{cccc}
\frac{1}{c_{11}} & \frac{1}{c_{12}} & \cdots & \frac{1}{c_{1 n}} \\
\frac{1}{c_{21}} & \frac{1}{c_{22}} & \cdots & \frac{1}{c_{2 n}} \\
\vdots & \vdots & \ddots & \vdots \\
\frac{1}{c_{n 1}} & \frac{1}{c_{n 2}} & & \frac{1}{c_{n n}}
\end{array}\right] \cdot\left[\begin{array}{c}
F_{1} \\
F_{2} \\
\vdots \\
F_{n}
\end{array}\right]=\left[\begin{array}{c}
\Delta z_{1} \\
\Delta z_{2} \\
\vdots \\
\Delta z_{n}
\end{array}\right]
$$

As already mentioned, the introduced forces $F_{i}$ as well as the stiffness $c_{i j}$ depend on the current ram position.
Figure 5 shows the basic software approach. In the first step, timer data and the position-time dependence of the ram are used to specify the ram positions for the following simulation. At these ram positions, the forming forces applied in each stage by the tool set are derived from the measured data. These forming forces provide the instantaneous force vector $\boldsymbol{F}(s)$ in equation (4). The dislocations of the stages caused by each force in each stage are evaluated using the measured press data. The ratio of dislocations and causative forces constitutes the instantaneous flexibility matrix $\mathbf{N}(s)$ (equation (4)). Multiplying $\mathbf{N}(s)$ by the force vector $\boldsymbol{F}(s)$ produces a dislocation sum for each stage. This can be done for each point of time/position of the ram during the forming process. The dislocation sum of each stage does not actually match the real existing dislocation of each stage under the load used as input for the calculation. The reason for this is that in equation (4) non-linear initial effects are superimposed. The sum of elastic deformations of the bottom platen and ram is determined for each stage (Fig. 6) by connecting the end-points of the ram with a straight line and subtracting this from the sums of dislocation for each stage.

\subsection{Dislocation between ram and bottom platen}

The calculation of the total dislocation of each stage in the press requires consideration of the deformation of the ram and bottom platen as well as the frame spring, bearing clearances, existing tolerances, and the properties of the drive. The bearing clearances and existing tolerances in particular cause the non-linear area of the curve in Fig. 6 (centre). These curves are based on press measurement data. This means that the dislocation effects of 


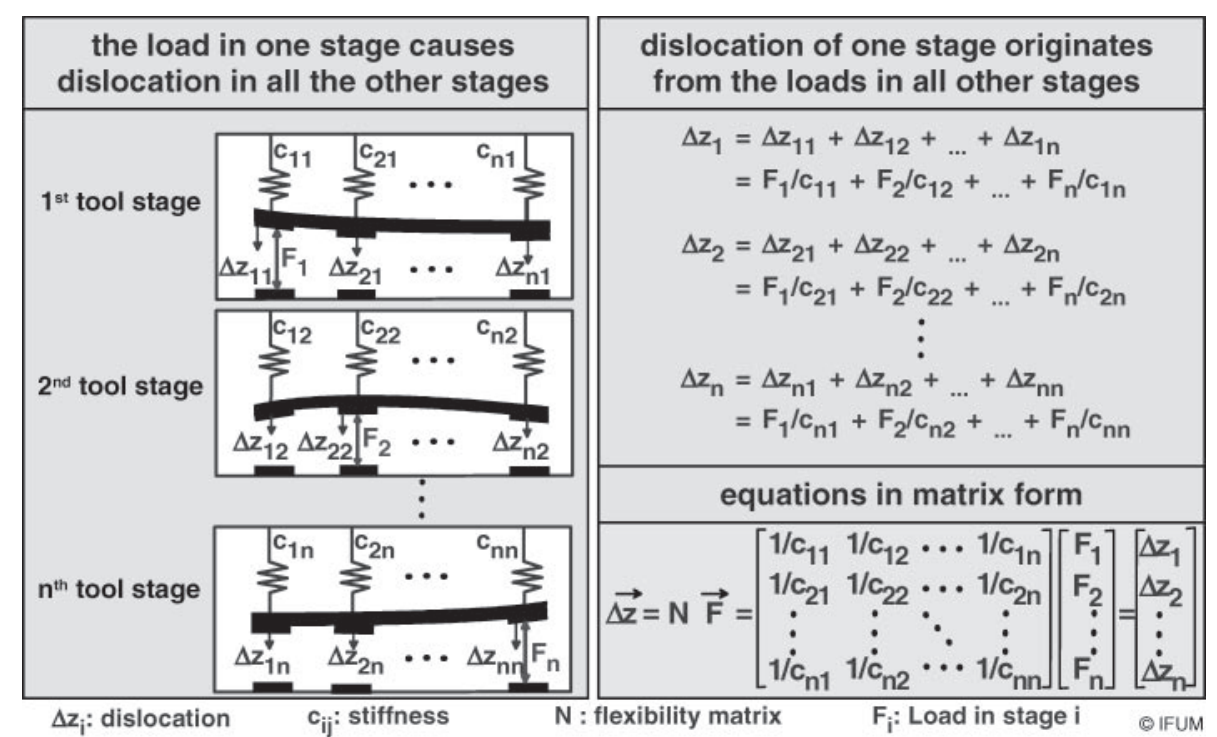

Fig. 4 Basic approach

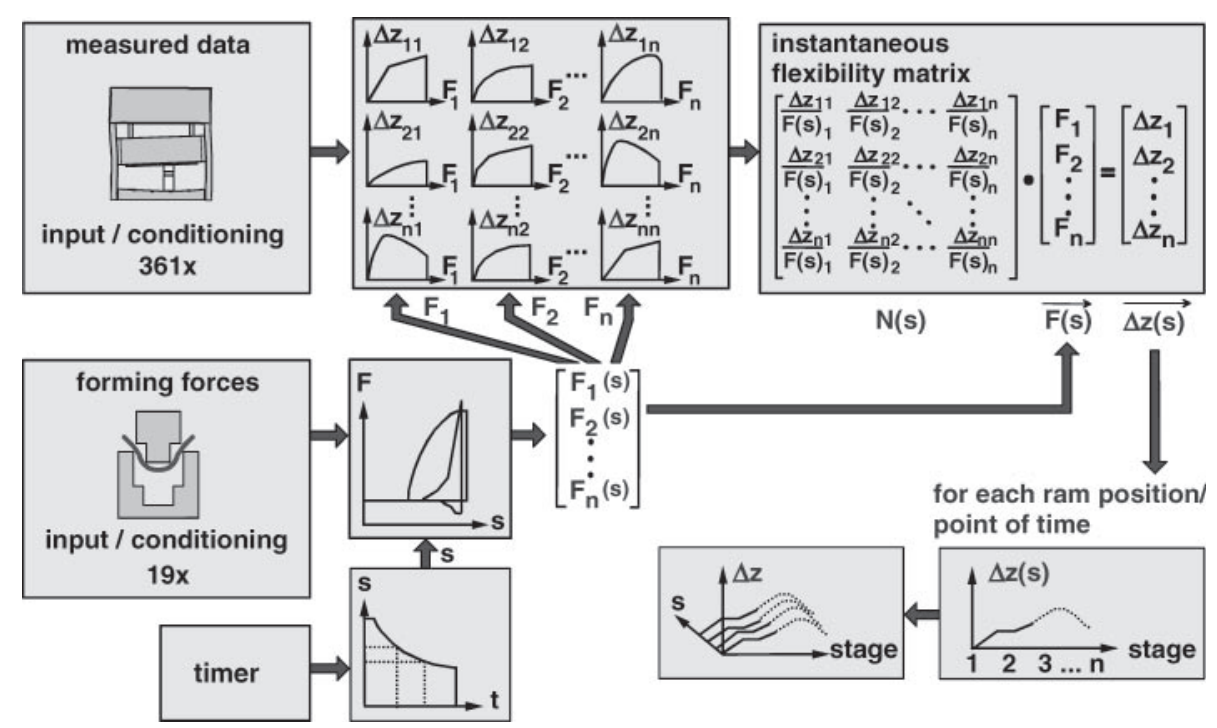

Fig. 5 Implementation of the basic approach in the software

applied variable loads cannot be superimposed. To avoid this problem, the forces of each stage are added and the strain point is evaluated. The strain point varies with ram location. With the sum of forces loading the press at the strain point [5], the dislocation of the ram (assumed to be inflexible) against the bottom platen (assumed to be inflexible) can be calculated by means of equation (4) (Fig. 6, right). Equation (4) can be used in this case because only one force is applied and the superimposition principle is complied with. The dislocation of the (inflexible) ram against the (inflexible) bottom platen computed under these conditions is now added to the sum of deformations of ram and bottom platen, calculated in section 4.1. The result is the total displacement between ram and bottom platen for each stage under load (Fig. 6, right bottom).

The software first computes the dislocation for each stage of the press while all stages are simultaneously under load. This load corresponds to a completely rigged press (Fig. 7, left top). The dislocation curves for each stage are then computed with only one stage of the press under load at any point in time (Fig. 7, bottom left). This load corresponds to the situation present during the daylight adjustment of the individual stages in the set-up process (step-by-step method). The program calculates the differences between the dislocations of the stages for the two loading cases. These differences are an indicator for the adjustment of the daylights, which 


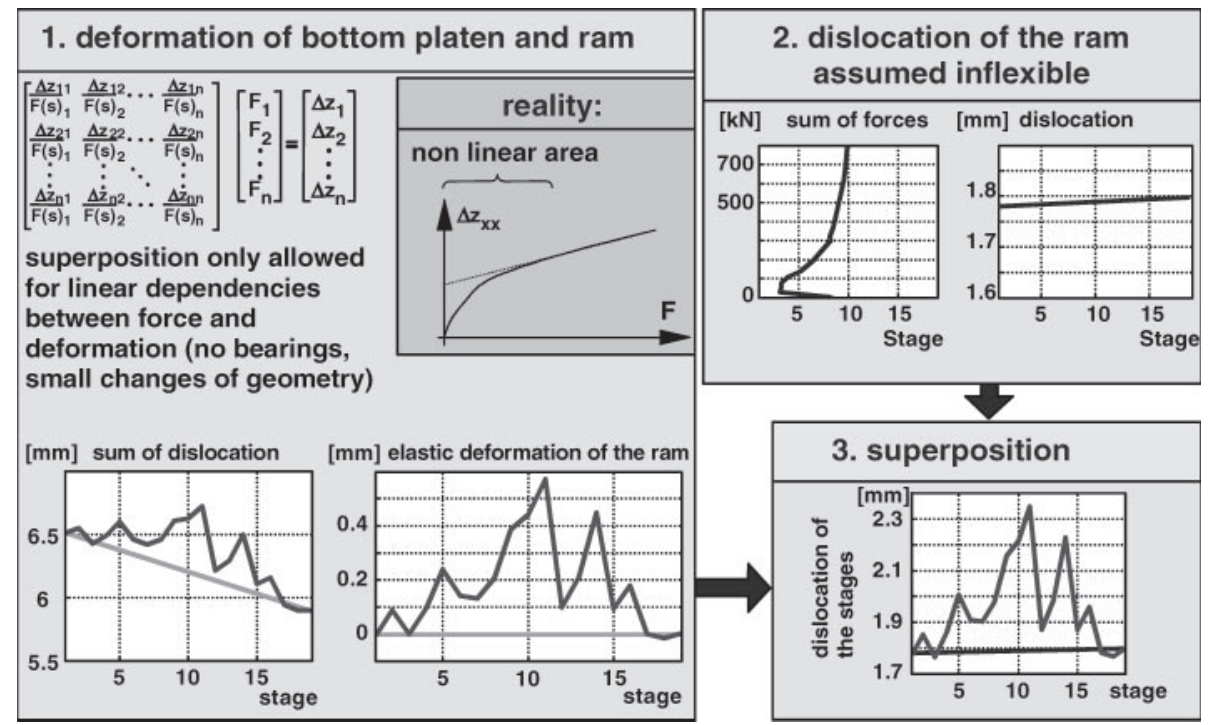

Fig. 6 Calculation and superimposition of deformation and dislocation

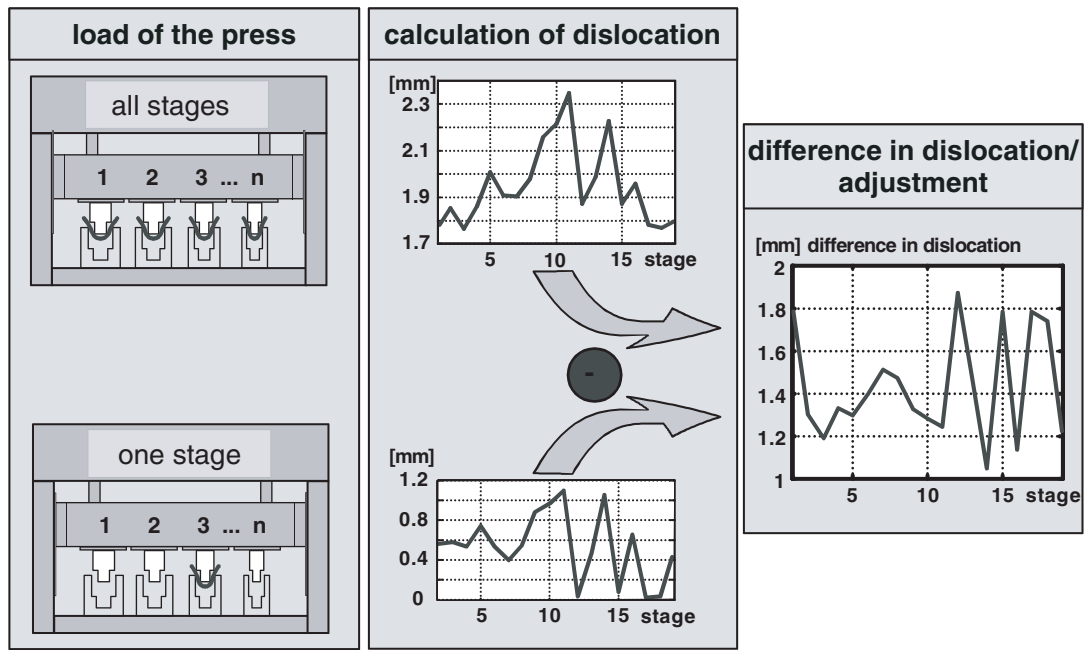

Fig. 7 Calculation of adjustment needed on the basis of differences

has to be done after the adjustment of the individual stages.

\section{VERIFICATION}

After measuring the force-path dependencies during the tool setting process for the rigged individual stages, the software calculates the displacement between ram and bottom platen for the press loaded by all stages as well as for the press loaded in each stage, one by one. For each stage the differences between the loading cases are calculated, and the daylights may be adjusted. In order to verify the function of the software and its basic approach, the displacements between ram and bottom platen were determined experimentally under different loading conditions. The daylight was measured with the machine at standstill as well as running with different tool setting states. The differences measured at standstill and running correspond to the dislocation between ram and bottom platen. Figure 8 shows the measured results at the bottom dead centre of dislocation between ram and bottom platen for the investigated press. The press was loaded with a complete tool set. The correlation of computed and measured dislocation values meets the expectations. The use of the developed software will shorten the time for the first installation of new tool sets substantially to the time needed for the installation of previously used tools. Fine adjustment will still be necessary. Cutting operations 


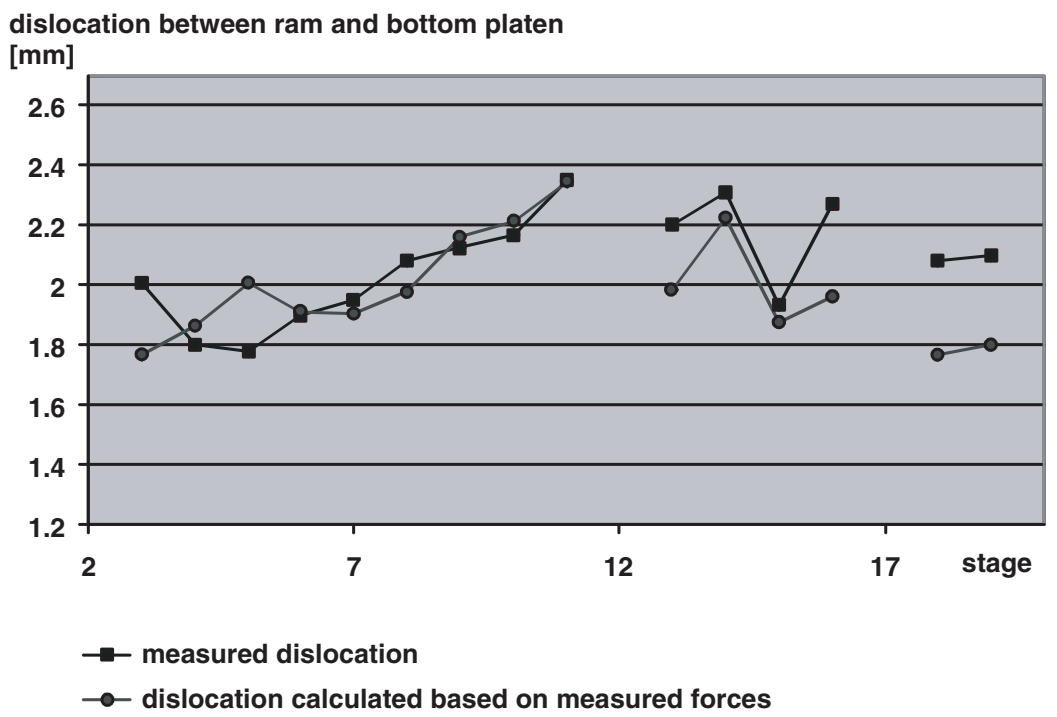

Fig. 8 Dislocation between ram and bottom platen with press fully adjusted

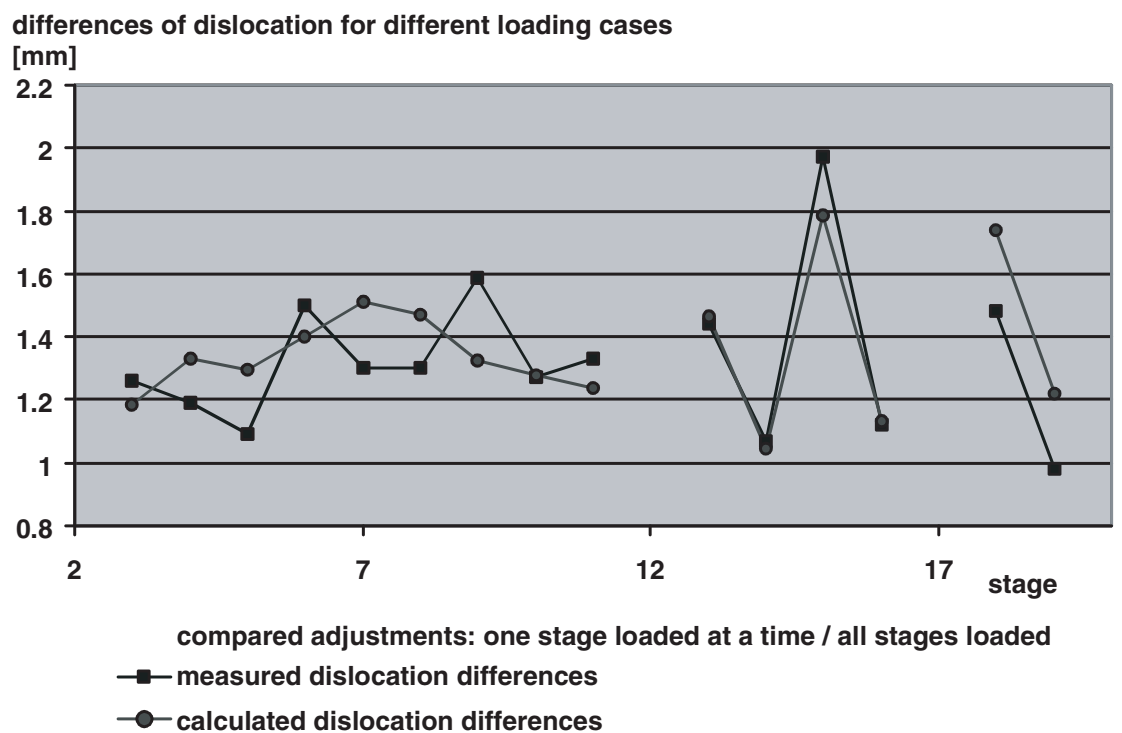

Fig. 9 Differences in dislocation between ram and bottom platen (press loaded by complete tool set compared with loading by one stage)

are performed in stages 1,12 , and 18 before the ram reaches bottom dead centre. In stage 17 , no tool stage is mounted. The geometry of the press made it impossible to measure the dislocation of stage 2 .

Deviations may arise owing to the measuring arrangement, which was realized with the aid of laboratory equipment under very cramped conditions. This fact reduces the reproducibility of the data to approximately $0.1 \mathrm{~mm}$. Stages 18 and 19 in particular are less certain.

Figure 9 shows the differences in dislocation of ram and bottom platen between a completely adjusted press and a press adjusted according to the step-by-step method. The calculated results and the measured results agree particularly in the highly loaded embossing stages in the centre of the press. This is a positive indication for the correctness of the software procedure and the basic approach. In explanation of the deviations in lightly loaded stages, it is remarked that, in addition to the above-mentioned measuring errors in stages 3 to 9, errors may be present in the assessment of the quality of intermediate parts. These comprise deepdrawing stages for which there are no clearly defined quality criteria. Sometimes they are only inspected visually. Because Fig. 9 is based on different tool setting processes, different quality evaluations are possible, which can lead to different adjusted daylights. 


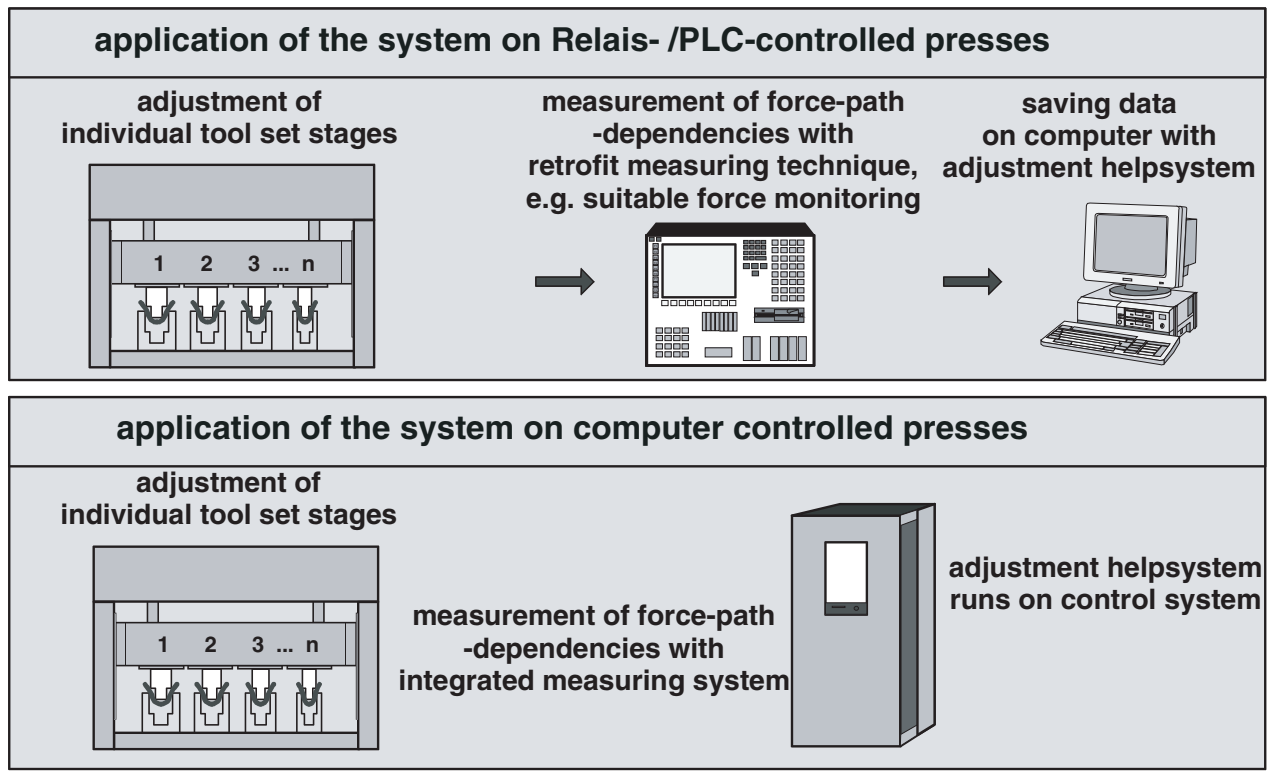

Fig. 10 Future prospects: software in manufacturing

\section{SUMMARY AND FUTURE PROSPECTS}

Increasing flexibility in manufacturing and making production processes leaner require shorter changeover times from one product to another. Mileham et al. [6] presents generic rules for designing the system of product, machine, tool, etc., to accelerate changeovers. Shingo and Robinson [7] developed systems to improve the modus operandi of tool set-up. This paper describes a program that uses measured machine properties and forming forces to shorten set-up time. In future investigations it will be attempted to speed up the repeated installation of existing tool sets. In such cases, there are sometimes grounds (e.g. instability phenomena $[\mathbf{8}, 9])$ requiring changes to the adjusted daylights of only one individual tool stage, without the different forces affecting the other stages. Further investigations will also indicate whether the software can calculate daylight adjustments needed by other stages. After further measurements to verify the software on another transfer press, an attempt is planned to couple the software with a suitable industrial measuring technique and then test the application in the manufacturing process. Options include applying the system to programmable logic controller (PLC) or computer-controlled presses (Fig. 10).

\section{ACKNOWLEDGEMENTS}

The authors would like to thank the European Research Association for Sheet Metal Working (EFB $\mathrm{eV}$ ). Research project AIF $12963 \mathrm{~N}$ was financed by the $\mathrm{EFB} \mathrm{eV}$ and the German Ministry of Economics and Labour (BMWA). The final report was published as an EFB research report and is available from the EFB office.

\section{REFERENCES}

1 Lüthi, R. Hochleistungs-Zuführsysteme und Werkzeugkonzepte für Präzisionsteile in hohen Stückzahlen. Paper available online: www.styner-bienz.com (accessed March 2006), 5 pp.

2 Transfer Press wins deep-draw and quick-turnaround contract work. Metalforming, 2002, (10), 28-31.

3 Pestel, E. Technische Mechanik, 1988 (BI Wissenschaftsverlag).

4 Wagener, H.-W. and Weikert, J. Messung der Tischund Stößeldurchbiegung an Torgestellpressen. Blech Rohre Profile, 1997, (44), 46-52.

5 Doege, E. and Krimm, R. Einarbeitungsanalyse von Tiefziehwerkzeugen. Research report AiF 12538, Forschungsvereinigung Werkzeugmaschinen und Fertigungstechnik eV, Frankfurt, 2002.

6 Mileham, A.-R., Culley, S.-J., Owen, G.-W., and McIntosh, R.-I. Design for changeover - a pre-requisite for lean manufacture. ISATA 28th International Symposium on Automotive technology and automation 1995, pp. 201-208.

7 Shingo, S. and Robinson A. Modern approaches to manufacturing improvement: the Shingo system, 1990 (Productivity Press, Cambridge, Massachusetts; Norwalk, Connecticut).

8 Doege, E. and Strasser, D. Instabilitäten bei Pressen für den Karosseriebau. Idee - Vision - Innovation (Eds F. Follertsen and M. Kleiner), 2001 (Verlag Meisenbach Bamberg).

9 Doege, E., Hütte, H., Kröff, A., and Strache, W. Genauigkeit im Presswerk - eine Voraussetzung für den Präzisionsbau. EFB-Kolloquium, Fellbach, Germany, 10-11 March 1998, EFB-Tagungsband T18, pp. 1-38. 